\section{Do cromático ao diatônico: as Mitológicas e o pensamento ameríndio}

Claude LÉVI-STRAUSS. A origem dos modos à mesa-Mitológicas 3. São Paulo, CosacNaify, 2006. 524 páginas..

\section{Marco Antonio Gonçalves}

A partir das fecundas hipóteses levi-straussianas contidas na tetralogia Mitológicas, podem-se reconhecer chaves de leitura instigantes para se pensar o universo mitológico ameríndio como constituído, necessariamente, por relações de transformação. Assim, o pensamento ameríndio é apresentado com base em fragmentos religados pela comparação, revelando um verdadeiro sistema em que as narrativas se interpenetram, o que possibilita desvelar códigos e temas conceituais que acentuam não apenas uma relação genético-histórica entre mitos, mas também demonstram a propriedade de determinadas feições e problemas que o pensamento ameríndio assume.

Lévi-Strauss conduz-nos rio abaixo, de bubuia, em sua canoa mitológica, fazendo-nos visitar muitas paisagens, percorrer atalhos por um caminho-temático principal, que geralmente coincide com os títulos pertencentes às Mitológicas $(O$ cru e o cozido; Do mel às cinzas; $A$ origem dos modos à mesa). Se a mitologia é o guia natural de Lévi-Strauss, os múltiplos temas abordados e os desvios percorridos vão aos poucos se juntando e, no fim das contas, os fios soltos atam-se novamente passando a ser um recomeço, porém, a partir de outro ponto de vista. Lévi-Strauss demonstra que, dependendo da perspectiva que se tome, o sentido do mito transforma a percepção do significado de natureza e de cultura. Assim, natureza e cultura são ferramentas conceituais mais do que significados cristalizados (p. 273).

Atravessando um continente, já que este terceiro volume adentra as planícies da América do Norte, Lévi-Strauss encontra relações entre pensamentos que põem em evidência os mesmos ingredientes e os mesmos problemas. Os mitos revelam uma propriedade continental, histórica, geográfica e, sobretudo, estrutural no seu sentido mais pleno:
"Já que a rã norte-americana ladra de crianças transforma uma mulher que toma um animal como amante, os frutos selvagens, que ela também aprecia muito, equivalem ao mel sedutor, que ocupa a mesma posição nos mitos da América do Sul em relação a uma rã ladra de crianças, e que, sendo um sedutor natural e alimentar, é o equivalente no sentido próprio do animal erótico" (p. 59). Pode-se, assim, comparar com base no mesmo código coisas que parecem estar muito distantes, como o mel e os frutos silvestres (pp. 57-58), mas que revelam afinidade: são perigosos mas atraentes, podem ser tóxicos ou deliciosos, daí uma determinada ambigüidade com sua classificação e, por isso mesmo, a importância que assumem para uma simbolização no pensamento ameríndio.

$A$ origem dos modos à mesa começa com o seu mito de referência: a narrativa amazônica de uma mulher grudenta e, portanto, sem modos. Partindo de um mito, o pensamento mitológico leva-nos a outros mitos e a muitos temas derivados - exemplo disso é o mito número 428 deste terceiro volume, que remete ao mito número 10 do primeiro volume da tetralogia, O cru e o cozido (p. 10). Dessa maneira, a estrutura das Mitológicas tende a coincidir com o próprio universo mitológico ameríndio, pois procura abranger sociedades que manifestam seu modo de ser por meio de um conjunto de mitos que compõem um sistema fechado.

Portanto, as conexões entre a América do Sul e a América do Norte se fazem através dos mitos, o que mostra a força do argumento do autor quando estabelece, por exemplo, uma associação natural entre a mulher-grampo e a mulherrã. Mesmo que estejam representando coisas distintas na mitologia dos dois continentes, exprimem o sentido mais estrutural de sua significação como "grudenta": num caso estaria mais relacionada ao sentido próprio, a mulher está literalmente grudada nas costas de seu marido; no outro é incapaz de se conformar com a separação de seu bem-amado e passa a ser grudenta no sentido figurado (p. 63).

Da mulher grudenta que não tem bons modos chega-se ao espaço propriamente simbólico e potente que a mulher ocupa no pensamento mítico ameríndio - fato que poderia ofender facilmente as feministas contemporâneas se fossem 
tomadas ao pé da letra as invocações da feminilidade na mitologia ameríndia. Para Lévi-Strauss, no entanto, a mulher, ou melhor, a condição feminina no mito é matéria de reflexão e não necessariamente uma representação de sua condição no mundo. A mulher e a semântica que engendra são, por assim dizer, contraditórias, mostrando os dilemas da descontinuidade, em que o pensamento ameríndio se apóia para resolver questões de ordem mais cosmológica e universal.

As Mitológicas poderiam também ser lidas como uma composição musical, cujo tema evidencia as linhas mestras do pensamento ameríndio e o seu modo de operação. Assim, o dilema apresentado pelo pensamento mítico é o mesmo proposto pela música, a passagem do cromático ao diatôni$\mathrm{co}$, dos pequenos e dos grandes intervalos ( $\mathrm{p}$. 172). Lévi-Strauss, ao se deparar com o material mítico americano, acentua a dialética entre os pequenos e os grandes intervalos: o cromático relacionado às contigüidades e o diatônico, às oposições que engendram a "boa diferença". Embora Lévi-Strauss enfatize que a intenção última do pensamento estaria ligada ao estabelecimento dos grandes intervalos e das oposições mais fundamentais, isto é, ao modo diatônico, reconhece que o cromatismo é recorrente no pensamento ameríndio. Acentuando a relação entre os pequenos intervalos, o pensamento ameríndio passa a operar a diferença por intermédio da contigüidade e da semelhança, encadeando uma série de mediações até atingir os grandes intervalos.

Assim, os três volumes que compõem as Mitológicas mostram que o modo de proceder do pensamento ameríndio percorre posições intermediárias entre os opostos. Planos de mediação que se interpõem entre elementos, transformando o que seria um dualismo (alto/baixo; céu/terra; vivos/mortos etc.) em processos contínuos de diferenciação e instaurando tríades ou cadeias de semelhanças a partir dos "pequenos intervalos". Boa parte da produção etnológica contemporânea tem-se dedicado a estas questões dos elementos mediadores (no parentesco, nas idéias cosmológicas, na mitologia, na arte) que produzem as contigüidades-diferenciais no processo de se produzir a diferença. Lévi-Strauss enfatiza que a semelhança ou a "pouca diferença” entre um caititu e uma queixada, com a qual os mitos trabalham, reforça a idéia de que a semelhança entre os dois porcos selvagens é extremamente significativa para se estabelecer uma diferença (Mit. 1, p. 112; Mit. 2, p. 83). A partir de traços mínimos, como comprido, curto etc., surge o "parecido" para estabelecer a diferença (Mit. 2, p. 82). Pássaros próximos como maritaca, periquito e papagaio produzem as diferenças entre seco e úmido, chuva e estio, savana e floresta (Mit. 2, pp. 70-71). A semelhança entre a ema e a seriema engendra a polarização das duas estações do ano (Mit. 2, p. 130).

O que comer e o modo de se comer ligam os três primeiros livros das Mitológicas, pondo em evidência a simbolização e a força de expressão do sentido que a predação tem no pensamento ameríndio. E neste mundo de mediações, o cromático ressurge na reflexão que o mito 361 (p. 38) propõe, em que a lua tem duas esposas com o mesmo nome, mas que estão situadas em espaços distintos - uma alimenta bem o marido e a outra o alimenta mal.

A questão essencial dos irmãos gêmeos é posta a partir dos intervalos mínimos que produzem a diferença: aparentemente iguais e semelhantes, mas essencialmente diferentes (p. 37). Abundam, também, nas Mitológicas exemplos de gêmeos (Mit. 1, pp. 204-205, 285), em que a semelhança é a garantia para se criar diferenças entre os irmãos que passam a ser mais velhos ou mais jovens, mais e menos espertos, um preguiçoso e outro desajeitado. A semelhança dos irmãos de mesmo sexo, mas não gêmeos, é outro recurso recorrente para instituir-se uma diferença: um irmão é mais forte do que o outro, mais destro, mais rápido. Agrega-se diferenças a um dos irmãos acentuando uma distinção, aumentando o intervalo entre eles. Lévi-Strauss pergunta-se por que os mitos necessitam duplicar personagens como cunhadas, irmãs, esposas; por que este pensamento recorre a uma duplicação de posições "parecidas" ou semelhantes. Para o autor, as duas cunhadas, no contexto de Do mel às cinzas, demonstram justamente a dualidade do mel, como alimento e como conotação sexual figurada. Duas irmãs, por causa da semelhança que apresentam, denotam duas qualidades distintas do mel, uma sexual e outra alimentícia. Essa duplicação dos personagens enfatiza uma ambigüidade 
que, segundo Lévi-Strauss, parece ser uma propriedade intrínseca da função simbólica. Nos mitos, tal ambigüidade se expressa por um código retórico que joga perpetuamente com a oposição da coisa e da palavra, do indivíduo e do nome que o designa, do sentido próprio e do figurado. Os personagens, embora semelhantes e duplicados, não ocupam as mesmas posições (Mit. 2, p. 170).

O arco-íris resolve uma contradição para Lévi-Strauss (p. 101), mas, por outro lado, poderia estar ligado ao cromático e, por este mesmo motivo, estaria associado ao acaso ou à ordem do acontecimento (e quem sabe à morte?), visto que aparece e desaparece: "os mitos sul-americanos situam o arco-íris, ou a cobra arco-íris, na origem do veneno de pesca e das epidemias, devido ao caráter maléfico que o pensamento indígena atribui ao cromatismo, tomado no sentido de reino dos pequenos intervalos. Por efeito de uma simples variação de afastamento entre seus termos, este reino gera um outro: o dos grandes intervalos" (Mit. 2, p. 267).

A ordenação dos animais em alguns mitos (pp. 113-114) faz-se pela contigüidade - voltamos, então, às questões acerca do contínuo e do descontínuo. A contigüidade cromática dos animais produz outra contigüidade, expressada no decorrer dos dias, do tempo, e que se realiza em pequenos ou grandes intervalos mediante a relação entre astros, sol, lua e constelações (ver, especialmente, pp. 326 e 382). Pode-se perceber essa maneira de proceder do pensamento ameríndio nos exemplos extraídos de um esboço construído a partir de valências semânticas em torno do sol e da lua, configurando pares de oposição: sol macho versus sol fêmea, sol tolo versus sol canibal, lua macho versus lua fêmea. Tal concepção revela uma das condições em que opera o pensamento ameríndio: a idéia de que o um contém o outro. A alteridade não se constrói por pares de oposição em que o eu estaria em oposição a um outro, mas, de fato, o eu se constrói e depende do não-eu, e não do outro como figura ontológica de alteridade para se constituir a diferença. A qualidade cromática deste pensamento leva LéviStrauss a reconhecer a potência criativa da mitologia, no sentido de que não se trata de uma mera reflexão sobre como funciona o universo. Os mitos avançam para um mundo imaginário tão potente que se pode, a partir daí, fazer associações as mais diversas, como ocorre a Lévi-Strauss quando associa as imagens produzidas na mitologia ameríndia ao imaginário criado nas pinturas de Hieronymus Bosch. Como exemplo cita a imagem evocada em um mito: "o macaco é também um homem e um jaguar, martela insistentemente o seu próprio nariz" (p. 115).

O autor, assim, rende-se às propriedades do pensamento mitológico, que instaura séries metonímicas transformadas em séries metafóricas, ou vice-versa. Isso evidencia o problema ontológico do pensamento ameríndio, qual seja, a relação entre contínuo e descontínuo, cromático e diatônico, pequenos e grandes intervalos, metonímia e metáfora. O pensamento mítico, ao refletir, por exemplo, sobre a questão de como se casar apresenta o problema da alteridade ameríndia expressa em muitos mitos $(88,98,127,154,161)$ a partir da exogamia e da endogamia, do próximo e do distante, do código sociológico e do código astrológico (sol e lua); questões centrais que nos reenviam à complexidade de ser um e/ou ser outro, o que evoca a questão da simultaneidade, da proximidade e da distância (p. 173).

Outro aspecto importante que surge na tetralogia, especialmente neste terceiro volume, é que a explicação sociológica depende de outras varáveis, como os códigos astronômicos, anatômicos, geográficos e cosmológicos. Isso mostra a complexidade do pensamento ameríndio, que não está encapsulado em razões sociológicas, mas realizase como possibilidades de interposições de códigos e camadas que se entrecruzam. Exemplo disso é a mulher cortada em pedaços (cap. 1) - seus pedaços estariam, por assim dizer, entrecruzando os códigos anatômico e astronômico, em que a descontinuidade do corpo gera a descontinuidade dos astros. Pode-se, ainda, caminhar num sentido contrário, quando a percepção da diferença entre os astros faz o código astrológico produzir uma diferença social, de onde se conclui que os sistemas de diferenças são um método para que o pensamento possa emergir e se manifestar. Mesmo sendo tais diferenças, num primeiro momento, mínimas ou contíguas (pp. 271-272), elas têm a potência de instaurar a diferença necessária para que o pensamento possa apresentar o mundo. 
Ao final do livro, Lévi-Strauss retorna à questão dos modos à mesa, evocando as regras da civilidade quando constrói seu famoso triângulo culinário estabelecendo uma relação complexa entre três eixos: o cru, o cozido e o podre. Porém, como o pensamento ameríndio opera pela lógica do sensível, sobre os grandes intervalos gerados precipitam-se múltiplas intermediações (assado, defumado e ensopado), de forma que tudo se remete, novamente, à questão do contínuo e do descontínuo como modo estruturador desse pensamento. Assim, o cromatismo, mesmo tendo como função última gerar intervalos maiores e ser percebido como algo negativo por estar mais próximo do contínuo, parece ser o princípio e o meio de o pensamento ameríndio se estruturar, o que cria dificuldades para o estabelecimento de dualismos puros, grandes intervalos definidos e inequívocos.

\section{MARCO ANTONIO GONÇALVES é professor do Programa de Pós-Graduação em Sociologia e Antropologia do IFCS-UFRJ (E- mail: marcoantonio@imagelink.com.br).}

\section{Deus na fronteira}

Paula MONTERO (org.). Deus na aldeia: missionários, indios e mediação cultural. São Paulo, Globo, 2006. 583 páginas.

\section{Oscar Calavia Sáez}

Um primeiro resumo é fácil: o pêndulo foi de um extremo a outro do seu trajeto e agora passa com mais vagar pelo centro da curva. Não faz muito tempo que a antropologia entendia as missões como não mais que uma frente ideológica destruidora da cultura e da socialidade indígena. Contra esse pessimismo levantou-se, mais recentemente, a noção das sociedades indígenas como máquinas de deglutir os credos, de anulá-los à força de inconstância ou de reduzi-los a uma estrutura indígena permanente, mal oculta sob os véus da nova religião. Agora, enfim, a atenção se volta para a positividade da missão: importam menos as totalidades que se encontram e mais a ação de um mediador que retira códigos de uma para inseri-los nas teias da outra; que quando espera reduzir está de fato a produzir algo novo. É mais provável, assim, que os missionários apareçam em sua concretude e variedade, e que o protagonismo dos índios se reconheça não na luta pela identidade, mas nas artes da alteração.

Esse resumo, porém, diz pouco sobre o livro organizado por Paula Montero, fruto de vários anos de pesquisas e debates coordenados, nos quais tive uma vez a honra de participar. A coletânea reúne onze autores, com pontos de partida muito diferentes: o estudo de conjuntos etnológicos regionais em que diversas modalidades de cristianismo colaboram para articular as diferenças entre os grupos; as reflexões sobre a emergência étnica com seu correspondente resgate cultural; os estudos sobre as relações entre estrutura e história; e, por fim, a revisão antropológica da antiga tupinologia. Mas o tópico focal do livro não é a história nem a etnologia indígenas: ele se encontra talvez na interseção entre os conceitos de religião e cultura, e no espelhamento entre os seus agentes, o missionário e o antropólogo. A missão seria a protoforma da mediação cultural, e, segundo Montero, examiná-la é uma boa opor- 